\title{
ESTUDO QUALI-QUANTITATIVO E DA PERCEPÇÃO DOS MORADORES EM RELAÇÃO À ARBORIZAÇÃO URBANA EM BAIRRO DE SETE LAGOAS (SETE LAGOAS, MG, BRASIL).
}

\author{
Nivia Labanca de Souza - nivia.labanca@gmail.com \\ Faculdade Santo Agostinho - Campus Sete Lagoas \\ Daniela Duarte Ventura Melo - danielalavras@yahoo.com.br \\ Faculdade Santo Agostinho \\ Ramon Lamar Oliveira Junior - ramonlamarjr@gmail.com \\ Faculdade Santo Agostinho
}




\section{RESUMO}

Para que a arborização urbana possa proporcionar todos os benefícios de que é capaz aos cidadãos, é necessário bom planejamento e estudos técnicos. Essa é a maneira destas áreas verdes colaborarem com a saúde mental, física e psicológica das pessoas. O presente estudo teve como objetivo a análise qualitativa e quantitativa da arborização urbana do entorno da Faculdade Santo Agostinho, abrangendo as ruas Atenas, Coimbra, Florença, Genebra, Milão, Nápolis, Nice e Turim, do bairro Jardim Europa, de Sete Lagoas, Minas Gerais. Também foi aplicado um questionário a 41 moradores dessas mesmas ruas escolhidos de modo aleatório, para avaliação da percepção sobre a arborização local. Foram identificados 100 indivíduos arbóreos de 24 espécies, sendo 15 nativas e 9 exóticas. Apenas 21 espécimes não mostraram sinais de podas incorretas. Alto grau de podridão e outros danos provocados principalmente por poda incorreta que sugerem a necessidade de supressão estão presentes em 14 dos espécimes analisados. Não foi observada a presença de plantas parasitas nos 100 indivíduos analisados. A quase totalidade dos moradores do entorno reconhece como principais vantagens da arborização a produção de sombra e sua capacidade de tornar o ar mais fresco. A principal desvantagem apontada relaciona-se com a escuridão e sensação de insegurança à noite. 56\% dos moradores têm o interesse de melhorar a arborização plantando e cuidando de alguma árvore em sua calçada. A quantidade de árvores por quilômetro de calçada e a área verde por habitante na região estudada ficou abaixo dos valores recomendados. As calçadas largas permitem que tal situação seja corrigida no futuro.

Palavra-chave: educação ambiental; florestas urbanas; serviços ambientais

\section{INTRODUÇÃO}

Mesmo diante dos empecilhos, não se deve privar a população do conforto e dos benefícios proporcionados pela arborização urbana, uma vez que é por meio dela que se obtém maior qualidade de vida. A arborização age simultaneamente sobre o lado físico e mental do homem, absorvendo ruídos e atenuando o calor do sol. Já foi comprovado que devido à arborização urbana pode haver diferença de temperatura de até $10^{\circ} \mathrm{C}$ entre o centro de cidade e sua periferia mais arborizada. No plano psicológico, a boa arborização diminui o sentimento de opressão do homem em relação às grandes edificações (FIGUERÊDO, 2010). 
O desenvolvimento nas grandes cidades tropicais é acompanhado por uma grande devastação da natureza, com destaque para uma intensa mudança da arborização urbana que dá lugar às edificações, deixando de lado a sua importância em amenizar os efeitos das condições microclimáticas (GOIS et al., 2012).

A sensação de bem-estar humano é condicionada a esses elementos climáticos sendo uma dos principais atributos das árvores contribuir para a melhoria do clima através da transpiração, retenção de poeira e partículas, redução da incidência direta de energia solar e atuação como barreira para a propagação de som (GREY; DENEKE, 1986).

O Objetivo deste trabalho é estudar a arborização das ruas Atenas, Coimbra, Florença, Genebra, Milão, Nápolis, Nice e Turim, do bairro Jardim Europa de Sete Lagoas, MG, que configuram o entorno da Faculdade Santo Agostinho de Sete Lagoas e captar a percepção dos moradores da mesma região em relação à arborização de suas ruas, visando identificar as características dos indivíduos arbóreos em seus aspectos qualitativos e quantitativos, o grau de satisfação dos moradores e seus anseios sobre o tema, de forma a permitir uma caracterização do estado atual da arborização do trecho estudado, bem como suas perspectivas futuras visando o bem de todos.

\section{METODOLOGIA}

O estudo foi realizado nas ruas Florença, Turim, Atenas, Milão, Nice, Genebra, Nápolis e Coimbra as quais encontram-se no entorno da Faculdade Santo Agostinho de Sete Lagoas (Fasasete), localizado em Sete Lagoas, MG, Brasil.

O trabalho consistiu, em sua fase de campo, de duas etapas. Na primeira etapa, foram identificadas as espécies arbóreas e tomados diversos parâmetros como altura da árvore, diâmetro da copa, DAP (diâmetro na altura do peito) determinado a partir do perímetro do tronco na altura do peito (CAP) dividido por 3,14, fuste (altura da árvore até a primeira bifurcação), largura da calçada, distância de construções e sinais de ataques de agressores biológicos como fungos, cupins, formigas e plantas parasitas. Ao longo dessa etapa foi realizado um diagnóstico preliminar das ações que deveriam ser tomadas, especialmente no tocante à poda e supressão.

Na segunda etapa, foi aplicado um questionário em cerca de $15 \%$ das residências, com o objetivo de traçar a percepção dos moradores em relação à importância da arborização urbana. 


\section{RESULTADOS E DISCUSSÃO}

A proporção entre os sexos e as idades dos entrevistados apresentou uma distribuição bastante regular, não havendo predomínio de um grupo sobre os demais. A satisfação dos moradores da região estudada com a arborização de suas ruas encontra-se na faixa de 33\%; ROPPA et al. (2007) encontraram na região estudada (Santa Maria, RS) satisfação na ordem de 49\%. Provavelmente tal percepção venha da escolha da "sombra" como a maior vantagem que se atribuiu à arborização urbana (escolhida por 39\% dos moradores), seguida de perto por "tornar o ar mais fresco" (escolhida por 37\%); observando-se que o morador poderia marca até duas opções. Em várias pesquisas similares (ROPPA et al. 2007, RIBEIRO, 2009) a preferência também se dá pela "sombra". Tal desejo de melhoria microclimática talvez seja explicada no local estudado se assumirmos uma possível correlação com o pequeno número de árvores por quilômetro de calçada.

Alguns moradores, durante a abordagem para apresentar o questionário, frisaram que não veem aspectos negativos na arborização, contudo "escuridão e insegurança" com 29 indicações, "danos às calçadas" com 21 e "queda de folhas" e "danos às casas" foram apontados por 19 moradores. Danos às calçadas também estão entre os mais lembrados nos estudos de RABER ; RABELATO (2010), RIBEIRO (2009) e ROPPA et al (2007). ROPPA et al. (2007) ainda citam como problemas mais graves, sob a ótica dos moradores, a sujeira nas ruas com 38,5\% e problemas com fiação aérea com 35,4\%.

Nas entrevistas ficou claro que os moradores mais idosos detêm uma maior preocupação e carinho com as árvores, mas não se sentem animados (ou em seu dizer "com saúde") para plantar e cuidar de mais árvores. A pequena presença de frutíferas de uso humano (apenas 5\% de indivíduos) pode indicar pouca participação da população na escolha do espécimes. Como afirmado por RIBEIRO (2009), o fato de $37 \%$ dos entrevistados não estarem dispostos a plantar mais árvores podem até ter consciência da importância do ato, mas não estão dispostos a fazê-lo.

\section{CONCLUSÕES}

- $\quad$ Foram encontrados 100 espécimes arbóreos com no mínimo 1,80 metro de altura e $15 \mathrm{~cm}$ de DAP no entorno da Faculdade Santo Agostinho, totalizando 24 espécies 
pertencentes a 15 famílias botânicas. As espécies nativas são 15, totalizando 81 indivíduos e as espécies exóticas são 9, totalizando 19 indivíduos.

- $\quad$ A altura média das árvores analisadas foi de $741 \pm 360 \mathrm{~cm}$, com diâmetro da copa médio de $545 \pm 309 \mathrm{~cm}$, DAP médio de $35 \pm 21 \mathrm{~cm}$ e fuste médio de $128 \pm 108 \mathrm{~cm}$. O baixo valor encontrado para o fuste médio indica que as mudas usadas não eram de boa qualidade. Mudas boas devem apresentar ao menos 1,80 metros de fuste, sendo o ideal acima de 2,50 metros.

- A área média permeável junto ao colo de cada árvore foi de $1715 \pm 1631 \mathrm{~cm}^{2}$. Nessa medição não foram consideradas 32 árvores que se encontravam em calçada sem pavimentação. Tal valor é baixo em relação ao mínimo desejado de um metro quadrado ou $10.000 \mathrm{~cm}^{2}$. A largura média das calçadas de $250 \pm 82 \mathrm{~cm}$ e o afastamento médio das construções de $143 \pm 66 \mathrm{~cm}$ permite maior área permeável.

- Conflitos com a fiação foram registrados em 17 casos. Já em 50 casos ocorreram danos ao pavimento da calçada e/ou guia pelas raízes. Com o crescimento das árvores e a pequena área permeável, é provável que esses números aumentem bastante no futuro.

- Podas mal executadas deixaram suas marcas em 38 indivíduos, considerando lesões de média e alta gravidade. 21 não apresentaram sinais de podas mal feitas.

- Podridão de média e alta gravidade foi encontrada em 38 indivíduos. 50 árvores não apresentaram sinais de podridão.

- Infestação de média e alta relevância por cupins foi detectado em 7 árvores, por formigas foi observado em 13 árvores.

- Plantas parasitas como erva-de-passarinho e cipó-chumbo não foram encontradas nos espécimes analisados, sugerindo que a baixa densidade de possíveis plantas hospedeiras, a altura das mesmas e o comportamento alimentar dos pássaros dispersores não colaboram para o sucesso dessa praga urbana.

- Verificou-se a necessidade de supressão de 16 árvores, devido a uma combinação de fatores, principalmente podas mal executadas, cupins e podridão.

- O cálculo de área verde por habitante foi feito considerando uma estimativa conservadora de 3 indivíduos por domicílio. A área verde por habitante assim verificada foi de $3,25 \mathrm{~m}^{2}$, valor muito aquém dos $15 \mathrm{~m}^{2}$ sugeridos pela Sociedade Brasileira de Arborização Urbana.

- Cerca de dois terços dos moradores entrevistados não estão satisfeitos com a arborização de suas ruas e $56 \%$ do total de moradores estão dispostos a plantar e cuidar de árvores nas calçadas. 
- A principal vantagem da arborização urbana apontada pelos moradores foi o fornecimento de sombra e melhoria da qualidade do ar (ar mais fresco) e a principal desvantagem está relacionada à segurança (escuridão), mas também referência a estrago de calçadas.

- As calçadas largas, a insatisfação com a arborização das ruas e a disposição da maioria dos moradores em plantar novas árvores permitem que a pouca relação de área verde por habitante seja corrigida no futuro.

Recomendamos que os órgãos públicos tenham mais atenção com a arborização urbana, uma vez que, além do benefício generalizado na vida e saúde dos cidadãos, ocorre a diminuição de gastos com sistemas de climatização, valorização de imóveis e melhoria dos aspectos estéticos da cidade.

\section{REFERÊNCIAS BIBLIOGRÁFICAS}

FIGUERÊDO, T. E. Levantamento Florístico e Análise Quali-Quantitativa da Arborização Urbana do Bairro Inocoop, localizado em Cruz das Almas-Bahia. Trabalho de Conclusão de Curso da UFRB, 2010.

GOIS, D. V., FIGUEIREDO, M. L. F. G., BARBOSA, E., MELO e SOUZA, R. O Processo de Apropriação da Natureza no Espaço Urbano em Cidades Tropicais: Problematizando a Distribuição de Ruas Verdes em Aracaju (SE). Revista Natural Resources, Aquidabã, v.2, n.1, 2012.

GREY, G. W.; DENEKE, F. J. Urban Forestry. 2. ed. New York: John Wiley, 1986.

GURGEL, C. S. Direito à Arborização Urbana. Revista Jus Navigandi, Teresina, ano 20, n. 4211, 11 jan. 2015. Disponível em: <https://jus.com.br/artigos/30098>. Acesso em: 24 nov. 2016.

OLIVEIRA-JUNIOR, R. L. Arborização urbana, planejamento e podas. Sete Lagoas, 1 out. 2010. Disponível em: <http://ramonlamar.blogspot.com.br/2010/10/arborizacao-urbanaplanejamento-e-podas.html> Acesso em: 24 nov. 2016

RABER, A. P., REBELATO, G. S. Arborização Viária do Município de Colorado, RS Brasil: Análise Quali-Quantitativa. Revista da Sociedade Brasileira de Arborização Urbana, Piracicaba - SP, v.5, n.1, 2010.

RIBEIRO, F. A. B. Arborização Urbana em Uberlândia: Percepção da População. Revista da Católica, Uberlândia, v. 1, n. 1, p. 224-237, 2009. Disponível em: <www.catolicaonline.com.br/revistadacatolica.>. Acesso em: 24 de jul. 2016 
ROPPA, C., FALKENBERG, J.R., STANGERLIN, D.M., BRUN, F.G.K., BRUN, E.J., LONGHI, S.J. - Diagnóstico da Percepção dos Moradores Sobre a Arborização Urbana na Vila Estação Colônia - Bairro Camobi, Santa Maria - RS. Revista da Sociedade Brasileira de Arborização Urbana, Piracicaba - SP, v.2, n.2, 2007. 